\title{
Effect of slow-release theophylline on nasal antigen challenge in subjects with allergic rhinitis
}

\author{
M. Aubier*, C. Neukirch*, M. Maachi*, D. Boucara*, R. Engelstätter**, \\ V. Steinijans**, R. Samoyeau+, M. Dehoux*
}

Effect of slow-release theophylline on nasal antigen challenge in subjects with allergic rhinitis. M. Aubier, C. Neukirch, M. Maachi, D. Boucara, R. Engelstätter, V. Steinijans, R. Samoyeau, M. Dehoux. CERS Journals Ltd 1998.

ABSTRACT: It has been recognized recently that theophylline possesses anti-inflammatory effects that could be of clinical interest in patients with airway inflammatory diseases such as asthma and allergic rhinitis (AR). The aim of the present study was to explore the effect of theophylline on the nasal eosinophilic inflammatory response following allergen challenge in patients with $A R$.

Fourteen subjects suffering from seasonal rhinitis with an early reaction after nasal allergen provocation were challenged outside the pollen season after pretreatment for 3 weeks with placebo or slow-release theophylline (Euphylong®) in a randomized double-blind, cross-over study. Nasal blocking index (NBI), nasal airway resistance and symptoms were recorded before, and 1 and $5 \mathrm{~h}$ after challenge; additionally, nasal lavage fluid was collected before, as well as 1 and $5 \mathrm{~h}$ after challenge. Eosinophil cationic protein (ECP) was measured in the lavage as well as the number of eosinophils before, and $1 \mathrm{~h}$ and $5 \mathrm{~h}$ after allergen challenge.

After 3 weeks of treatment, baseline concentrations of ECP in nasal lavage amounted to $826 \pm 329 \mathrm{ng} \cdot \mathrm{L}^{-1}$ (placebo) and $936 \pm 351 \mathrm{ng} \cdot \mathrm{L}^{-1}$ (theophylline). The ECP levels did not increase during the early phase response. Five hours after challenge, ECP in the placebo group increased markedly $(p<0.01)$, whereas no significant increase was observed during theophylline treatment. In parallel, the number of eosinophils in the nasal lavage fluid was lower during theophylline treatment. Additionally, theophylline therapy also significantly reduced the nasal symptoms and had some protective effect against nasal obstruction following allergen challenge.

These results confirm the anti-inflammatory effects of theophylline and suggest that these effects may be of clinical benefit in patients with allergic rhinitis.

Eur Respir J 1998; 11: 1105-1110.
*Unité de Pneumologie, Hôpital BICHAT, Paris, France. **Byk Gulden Pharmaceuticals, Konstanz, Germany. +Laboratoires Byk France, Le Mée-sur-Seine, France.

Correspondence: M. Aubier

Unité Pneumologie - 8è Sud

Hôpital BICHAT

46, rue Henri Huchard

75018 Paris

France

Fax: 33140258818

Keywords: Allergic rhinitis

ECP

eosinophils

inflammation

theophylline

Received: July 71997

Accepted after revision January 291998
Allergic rhinitis, the most common form of atopic disease, has an estimated prevalence ranging from 5-22\% [1]. It is now widely accepted that allergic rhinitis is sustained by an inflammatory response. Allergic mucosal inflammation is characterized by the presence of cell infiltration, predominantly with immunoglobulin (Ig)E-sensitized mast cells and activated eosinophils. The number of eosinophils in nasal secretions are increased during natural exposure to allergen [2], and a similar increase occurs during both the immediate and late-phase response to nasal provocation with allergen [3]. Nasal secretions in allergic rhinitis contain ECP (eosinophil cationic protein) that is cytotoxic for nasal epithelial cells [4] and leukotriene $\mathrm{C}_{4}[5]$ that increases nasal resistance and is the major leukotriene product of activated eosinophils [6].

Theophylline has been used for more than 50 yrs in the treatment of asthma and is still the most widely used anti-asthmatic therapy worldwide. Originally, its efficacy has been attributed primarily to its bronchodilating effect; however, during recent years it has been recognized that theophylline also possesses anti-inflammatory and immunomodulatory effects [7-10]. For asthmatic patients, it was demonstrated that theophylline therapy is equally effective with low dose budesonide therapy $\left(400 \mathrm{mg} \cdot \mathrm{day}^{-1}\right)$ in reducing the serum ECP concentration after 6 months of treatment [11]. Also, in asthmatic patients, Sullvan et al. [8] observed that theophylline could reduce the infiltration of activated eosinophils into the lung during the allergic late phase reaction. There is also increasing evidence that these effects are mediated by nonselective inhibition of phosphodiesterase isoenzymes [12].

There is limited information available about the effect of theophylline on allergic rhinitis. Treatment out of season of asymptomatic patients with rhinitis for 1 week with theophylline reduced both the release of mediators from mast cells and sneezing after nasal challenge [13]. Another study demonstrated that in patients with allergic rhinitis 4 weeks of treatment with theophylline resulted in a distinct decrease in bronchial hyperreactivity to carbachol [14]. At the same time, lung function which was normal in those patients remained unchanged. The authors speculated that this protective effect might be related, at least in part, to an anti-inflammatory effect of theophylline not only in the lower, but also in the upper, airways. 
In order to explore the potential anti-inflammatory effects of theophylline further, we performed consecutive measurements of ECP in nasal lavage fluid in patients with allergic rhinitis after allergen challenge before and after pretreatment with theophylline. This was of particular interest since, in a previous study [15], budesonide treatment was shown to inhibit the increase in ECP in nasal lavage during the late phase reaction. In addition, nasal airway resistance (NAR), oral peak expiratory flow (PEF) and nasal PEF were determined.

\section{Patients and methods}

\section{Patients}

Fourteen Caucasian volunteers (nine males) participated in the study after having given their written informed consent. Their mean age was 27 yrs (range: 19-33 yrs). All volunteers gave histories (during the last two or more yrs) of rhinitis during May and June with or without mild nasal symptoms outside the pollen season. All had a positive skin prick test to grass pollens with the appropriate antigen extract ( $>4 \mathrm{~mm}$ wheal, $>20 \mathrm{~mm}$ flare, with a extract concentration of $\partial 10$ protein nitrogen units $\left.\cdot \mathrm{mL}^{-1}\right)$. No history of other allergies such as house dust mite or animal dander was reported, and skin-prick tests to these allergens were negative. One subject also had asthma and used salbutamol on demand. Otherwise, no concomitant medication was given during the course of the study. The study was performed outside the pollen season. Careful examination of sinus radiographs (absence of opacification of both maxillary sinuses, mucosal thickening, or airfluid level on occipital-mental view) excluded sinusitis in all subjects. A rhinoscopic examination was also performed, which did not show any structural abnormality or signs of ongoing rhinitis in the 14 subjects.

\section{Design of the study and treatment}

This was a randomized, cross-over, double-blind study. Each patient was studied on three different days. The tests were always conducted at the same time of the day (15:00 h). The patients studied received either theophylline (10 $\mathrm{mg} \cdot \mathrm{kg}$ body weight ${ }^{-1}$. $\left.^{-1} \mathrm{y}^{-1}\right)$ taken orally twice a day or an identical placebo. Nasal allergen challenge and subsequent measurements (see below) were performed on three occasions: at baseline, 3 weeks after the first treatment (with either theophylline or placebo), and 3 weeks after the second treatment. After 1 week, blood was drawn for the determination of theophylline serum levels, and the results were reviewed by an independent observer. If necessary, the dose of theophylline was adjusted to obtain a therapeutic plasma level between 10 and $15 \mathrm{mg} \cdot \mathrm{L}^{-1}$.

There was no wash-out between the treatment periods since the measurements (theophylline and placebo) were performed at the end of the 3 weeks during which the subjects had received either placebo or theophylline. All the data collected at the end of the placebo or theophylline periods were compared to the data obtained during the baseline period. A carry-over effect of theophylline treatment on the placebo period is unlikely since there was a long interval ( 3 weeks) between the measurements. Furthermore, the theophylline plasma level was undetectable at day 8 of the placebo period irrespective of whether the subjects had started with placebo or theophylline. The study protocol was approved by the Ethics Committee of the hospital.

\section{Experimental procedures}

Allergens were delivered into the nostrils via a commercially available, hand-held atomizer used for topical nasal therapy (Nostrilla nasal spray; Boehringer Ingelheim, Ridgefield, CT, USA), which delivers $0.07 \mathrm{~mL}$-activation $^{-1}$. During the baseline period, the allergen challenge was started with two baseline measurements of NAR by active anterior rhinomanometry (Rhinomat, MEDIPROM, France) made at $15 \mathrm{~min}$ intervals. After these measurements were made, the diluent (saline albumin $0.03 \%$ ) was instilled into both nostrils, and NAR was measured 5 min in both nostrils thereafter. Subsequently, increasing doses $\left(0.2,0.5,0.8,1.8,2.8\right.$ IR) of allergen (Stallergenes ${ }^{\circledR}$, a mixture of five different grass pollens) were instilled into both nostrils until NAR measured 5 min thereafter had increased by at least $60 \%$ compared to the diluent. Measurements of NAR were repeated 1 and $5 \mathrm{~h}$ after the challenge.

Nasal and oral peak flows (mini-Wright peak flow meter (Clement Clarke International, Ltd, London, UK)) were recorded before, as well as 1 and $5 \mathrm{~h}$ after, challenge. Nasal patency was assessed with a mini-Wright peak expiratory flow meter with a face mask attached. After nasal and oral peak expiratory flow rates (PEFRs) were determined in triplicate, the best values were used to calculate the nasal blocking index (NBI) as follows [16]:

$$
\mathrm{NBI}=\frac{\text { Oral peak flow rate }- \text { nasal peak flow rate }}{\text { Oral peak flow rate }}
$$

Nasals symptoms were evaluated as follows: sneezing: none, 0 points; $1-3,1$ point; $>3,2$ points; rhinorrhea: none, 0 points; mild 1 point; abundant, 2 points; congestion: none, 0 points; mild 1 point; complete (bilateral), 2 points; pruritus: none, 0 points; mild (eyes or throat), 1 point; severe (eyes and throat), 2 points. Scores were determined before the challenge, 10 min after each allergen dose and 1, 3 and $5 \mathrm{~h}$ after the challenge.

During the treatment periods, the allergen dose was increased stepwise up to the dose that had caused an increase in NAR of at least $60 \%$ during the baseline period. Otherwise, the procedures and time-points for recording NAR, nasal and oral peak flow, and symptoms were identical.

Additionally, a nasal lavage was performed before instillation of the diluent and 1 and $5 \mathrm{~h}$ after the challenge. The challenged nostril was lavaged with $5 \mathrm{~mL}$ of saline solution, warmed to $37^{\circ} \mathrm{C}$ with the patient's neck extended and soft palate closed. After $10 \mathrm{~s}$ the lavage fluid was recovered by using a small catheter and gentle suction.

The nasal fluids were immediately centrifuged after the washing procedure (10 min-2,000 rpm). The supernatants were then aliquoted and frozen within $1 \mathrm{~h}$ at $-80^{\circ} \mathrm{C}$ until the mediator and protein assays were performed.

Cells were resuspended in $100 \mu \mathrm{L} \mathrm{PBS}$, and a total cell count was performed. An aliquot of cell suspension was 
cytocentrifuged, air dried, and stained using the MayGrünwald-Giemsa stain. A differential count was performed on a minimum of 100 cells.

The concentration of ECP in lavage fluid and in serum was subsequently measured with a double-antibody radioimmunoassay (RIA). ECP assay was performed as described by the manufacturers (Kabi Pharmacia Diagnostics, Saint Quentin en Yvelines, France). The detection limit was $2 \mu \mathrm{g} \cdot \mathrm{L}^{-1}$ with an intra- and inter-assay variation of 7 and $12 \%$, respectively. Albumin was also measured in lavage fluid by an enzyme-linked immunosorbent assay (ELISA) as previously described [16]. The detection limit was $1 \mu \mathrm{g} \cdot \mathrm{L}^{-1}$ with an intra- and inter-assay variation of 5 and $8 \%$, respectively. Cell counts were also performed in each lavage. The differentiation among eosinophils, neutrophils and epithelial cells was obtained by May-Grünwald-Giemsa staining. The number of inflammatory cells (neutrophils, eosinophils) was evaluated by counting the absolute number of each cell type at 250 -fold magnification in 25 microscopic fields spread over the whole slide [17]. Specimens were examined microscopically by a technician who was not directly involved in the study and who was unaware of the clinical data.

During the treatment periods, theophylline serum levels were determined before the start of the challenge. Thereafter, the last capsule of the trial medication was swallowed. In patients 6-14, additional theophylline serum measurements were performed $6 \mathrm{~h}$ after the last dosing.

\section{Statistical analysis}

All the results are expressed as mean \pm SEM. The Wilcoxon signed-rank test was used to compare subjects; 1) for each treatment period between baseline and 1 and $5 \mathrm{~h}$ after allergen challenge, and; 2) for each time-point, between theophylline and placebo treatment. Correlations between the different parameters were performed using Spearman's test.

\section{Results}

\section{Symptoms, peak flow measurements and NAR}

Following nasal allergen challenge, all patients exhibited sneezing, rhinorrea, pruritus and nasal obstruction as shown in fig. 1. A significant increase in the clinical score, as compared to the prechallenged clinical score, was observed during the placebo period 1 and $5 \mathrm{~h}$ after the nasal challenge (pð0.005). During the theophylline period, a significant increase in the nasal clinical score was also observed at $1 \mathrm{~h}$ (pð0.005), whereas at $5 \mathrm{~h}$, there was no significant increase in clinical score as compared to the prechallenge values. When compared with the placebo period, the clinical score during the theophylline period was significantly lower at $1 \mathrm{~h}$ (placebo $3.46 \pm 0.38 \mathrm{vs}$ theophylline $2.18 \pm 0.18, \mathrm{p} ð 0.05$ ) and at $5 \mathrm{~h}$ (placebo $1.64 \pm 0.4$ vs theophylline $0.72 \pm 0.15$, pð0.05).

Nasal obstruction, as assessed by NBI, followed a similar pattern to the clinical score (fig. 2). NBI was significantly increased at $1 \mathrm{~h}(\mathrm{p}<0.01)$, compared with the

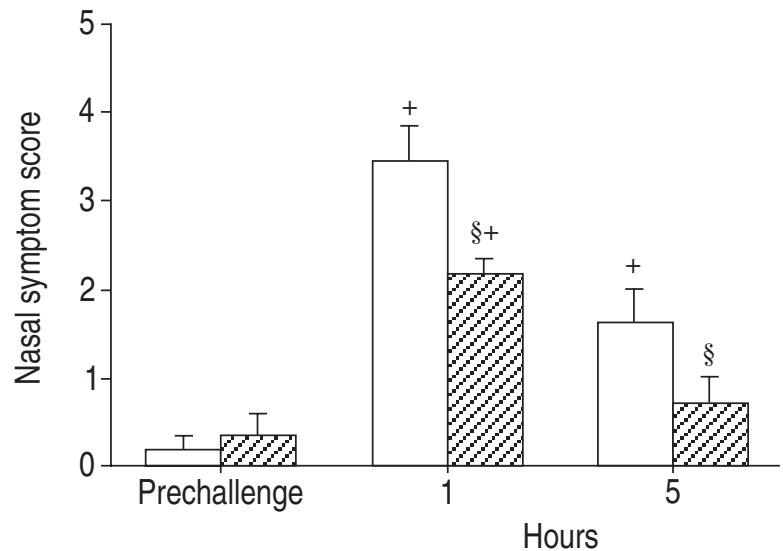

Fig. 1. - Mean values \pm SEM of nasal symptom scores before nasal challenge, at $1 \mathrm{~h}$ and $5 \mathrm{~h}$ after nasal allergen challenge. $\square$ : placebo; $\square$ : theophylline. $+: \mathrm{p} \leq 0.005$ as compared with prechallenge; $\S: \mathrm{p} \leq 0.05$ theophylline $v s$ placebo.

prechallenge values, both the placebo and treatment. A significant increase in NBI, as compared to before nasal challenge, was still observed at $5 \mathrm{~h}$ with placebo (pð0.01) but not with theophylline.

In figure 2, the mean values of NAR are shown for the theophylline and placebo periods. It should be noted that the prechallenge values were lower during the theophylline period than during the placebo period. Nasal challenge at $1 \mathrm{~h}$ and at $5 \mathrm{~h}$ induced an increase in NAR during the placebo and theophylline trial periods. The difference
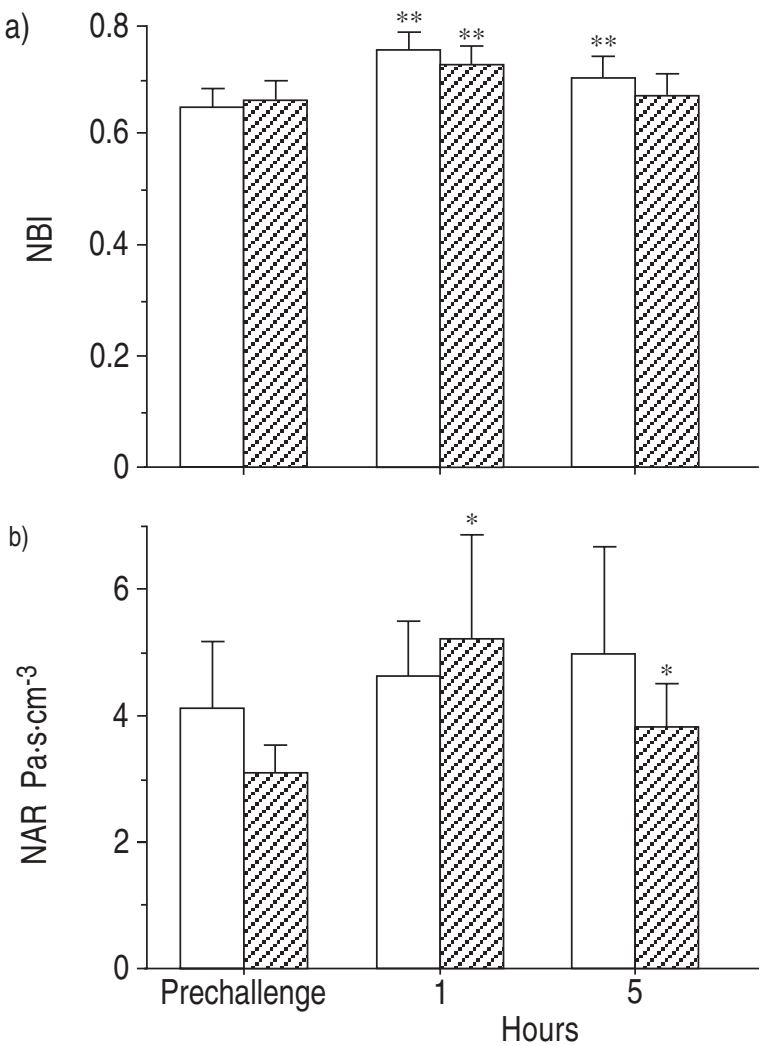

Fig. 2. - a) mean values \pm SEM of nasal blocking index (NBI) before nasal challenge, at $1 \mathrm{~h}$ and $5 \mathrm{~h}$ after nasal challenge. b) mean values \pm SEM of nasal airway resistance (NAR) before nasal challenge, at $1 \mathrm{~h}$ and $5 \mathrm{~h}$ after nasal challenge. $\square$ : placebo; $\square$ : theophylline. ${ }^{*}, * *: \mathrm{p} \leq 0.05, \mathrm{p}<0.01$ as compared with prechallenge. 
between the placebo and theophylline was not statistically significant. NAR was significantly higher than the prechallenge values during theophylline treatment $(\mathrm{p}<0.05)$.

\section{Lavage}

Except for epithelial cells (= majority of cells), eosinophils and neutrophils, no other cell types were recovered. The volume recovered was $4.17 \pm 0.3 \mathrm{~mL}$.

The number of neutrophils per nasal lavage was significantly higher (pð0.05) at $1 \mathrm{~h}$ and $5 \mathrm{~h}$ as compared to the prechallenge values during the placebo period, whereas no significant difference with the prechallenge values was noted during the theophylline period (fig. 3).

No significant change in the number of eosinophils, as compared to the prechallenge values, was noted after nasal challenge during the theophylline period at $1 \mathrm{~h}$ and $5 \mathrm{~h}$ (fig. 3). By contrast, during the placebo period, a significant increase in eosinophils per nasal lavage, as compared to the prechallenge values (pð0.005) occurred at $5 \mathrm{~h}$. Baseline readings in ECP levels prior to challenge were very comparable for placebo and theophylline, and no significant change was seen $1 \mathrm{~h}$ after challenge. ECP levels measured at $5 \mathrm{~h}$ during placebo treatment were significantly higher compared to the control challenge (pð0.005), whereas it was not significantly different during theophylline treatment $(\mathrm{p}=0.2)$ (fig. 4). A significant correlation was observed between the changes in eosinophils and ECP during theophylline period $(\mathrm{p}<0.01$ and $\mathrm{p}<0.03,1 \mathrm{~h}$ and $5 \mathrm{~h}$ after nasal challenge, respectively).
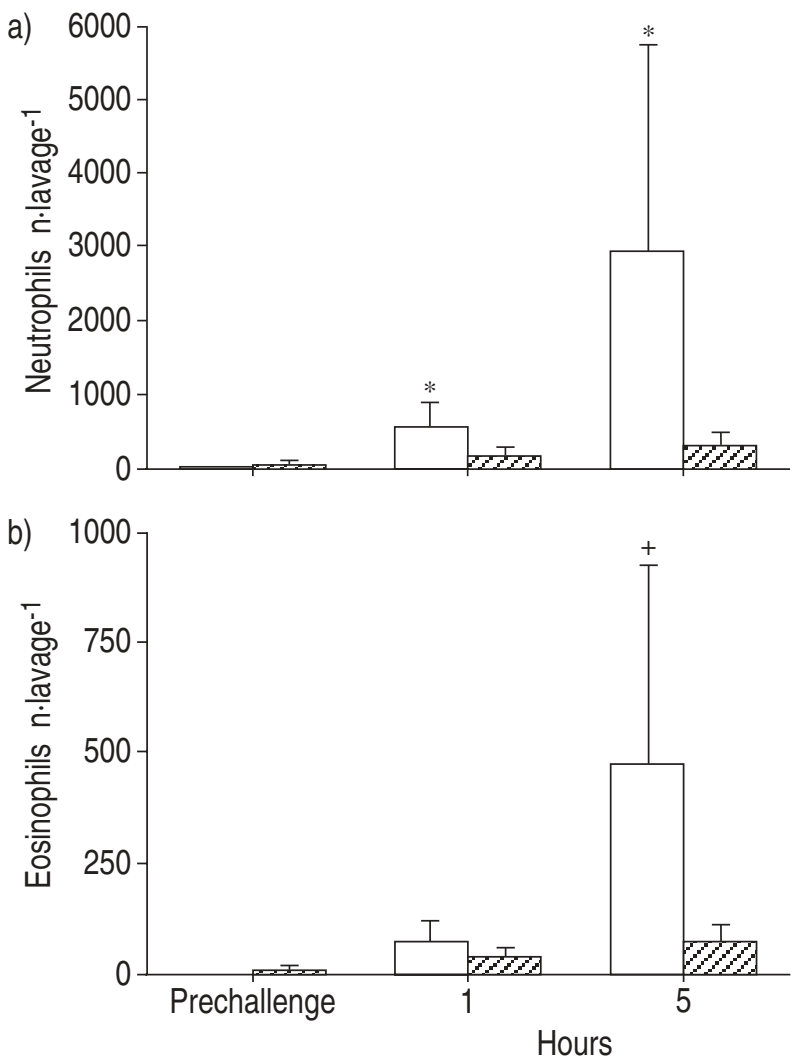

Fig. 3. - Mean values \pm SEM of the number of: a) neutrophils $\cdot \mathrm{mL}^{-1}$ and b) eosinophils $\cdot \mathrm{mL}^{-1}$ of nasal lavage before nasal challenge, at $1 \mathrm{~h}$ and 5 h after nasal challenge. $\square$ : placebo; $2 \geqslant$ : theophylline. $*: \mathrm{p}<0.05 ;+\mathrm{p} \leq$ 0.005 , as compared with prechallenge.

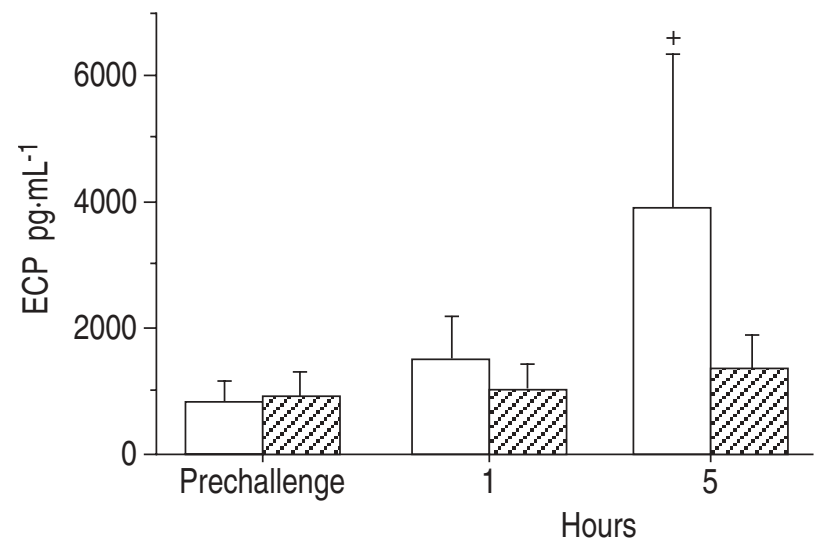

Fig. 4. - Mean values \pm SEM of the concentration of eosinophil cationic protein $(\mathrm{ECP}) \cdot \mathrm{mL}^{-1}$ of nasal lavage before nasal challenge, at $1 \mathrm{~h}$ and 5 $\mathrm{h}$ after nasal challenge. $\square$ : placebo; $Q Z$ : theophylline. ${ }^{+}: \mathrm{p} \leq 0.005$, as compared with prechallenge.

No significant change in the serum level of ECP, as compared to the prechallenge value, was noted at any time with either placebo $\left(7.8 \pm 2,6.3 \pm 1.7,5.7 \pm 1.5 \mu \mathrm{g} \cdot \mathrm{mL}^{-1}\right.$ at prechallenge, $1 \mathrm{~h}$ and $5 \mathrm{~h}$, respectively) or theophylline $\left(10.2 \pm 2.3,9.2 \pm 2.8,12.2 \pm 3.5 \mu \mathrm{g} \cdot \mathrm{mL}^{-1}\right.$ at prechallenge, $1 \mathrm{~h}$ and $5 \mathrm{~h}$ ).

Five hours after challenge, albumin increased by $100 \%$ during the placebo period as compared to the baseline, whereas during the theophylline period, the increase amounted to only $43 \%\left(9,626 \pm 4,493\right.$ and $3,629 \pm 1,455 \mu \mathrm{g} \cdot \mathrm{L}^{-1}$ respectively).

\section{Theophylline serum concentrations}

The morning theophylline serum concentrations were $10.0 \pm 0.55 \mathrm{mg} \cdot \mathrm{L}^{-1}$. The serum concentrations $6 \mathrm{~h}$ thereafter were $12.6 \pm 0.6 \mathrm{mg} \cdot \mathrm{L}^{-1}(\mathrm{n}=9)$.

\section{Adverse events}

Seven subjects reported adverse events (nausea and vomiting, headache, palpitations, trembling, insomnia, stomach pain, diarrhoea, polyuria) during the theophylline treatment period and three during the placebo period (headache, palpitations, insomnia, pharyngitis). The adverse events were usually mild and transient. No subject withdrew from the trial because of adverse events.

\section{Discussion}

We have shown that, compared with the placebo, 3 week treatment with oral slow-release theophylline decreases symptoms, prevents nasal obstruction, and reduces the influx of eosinophils as well as the increase in ECP concentration in nasal lavage fluid after allergen challenge.

The clinical effects of theophylline observed in our study occurred at serum concentrations in the therapeutic range of $8-15 \mathrm{mg} \cdot \mathrm{L}^{-1}$. Treatment of asthmatic patients suffering from concomitant rhinitis with theophylline thus offers the chance of treating both diseases with one drug. 
In a previous study [14], it has been shown that theophylline was able to decrease the bronchial responsiveness significantly in patients with allergic rhinitis. In contrast, bronchial inhaled steroids do not affect allergic inflammation in the nose [18], contrary to topical nasal or oral steroids $[18,19]$. In this context, it should be noted that in a study of patients with bronchial hyperreactivity not associated with upper airway disease, theophylline had no effect on bronchial responsiveness [20].

The changes in ECP concentration in nasal lavage fluid observed in our study with theophylline as compared to the placebo are consistent with an effect of the drug on eosinophils. In this study, we observed that during the placebo period, allergen challenge increases eosinophils and neutrophils in the nasal lavage-fluid at both 1 and $5 \mathrm{~h}$. It should be noted, however, that the number of cells recovered in our patients was lower than the number reported in a previous study in similar patients [21]. This difference may be due to the technique of nasal fluid recovery. Indeed, in the latter study, the nasal secretions were directly collected by having the patient blow his or her nose into a polyethylene sheet. In our study, saline was first instillated, and the fluid was then recovered by gentle suction using a small catheter. The latter procedure certainly diluted the nasal secretions markedly and in turn led to the recovery of fewer cells. Nevertheless, theophylline markedly inhibited the increase in eosinophils after allergen challenge and particularly at $5 \mathrm{~h}$, as compared to the placebo period. This effect on ECP is consistent with recent work that has shown that 6 months treatment with oral theophylline reduces the concentration of plasma ECP in asthmatic subjects [14]. In that study, theophylline was equally effective to a low dose of inhaled budesonide (400 $\left.\mathrm{mg} \cdot \mathrm{day}^{-1}\right)$. It should be noted, however, that the full antiinflammatory effect of inhaled steroids is reached within 4-6 weeks after the onset of administration, whereas the onset of action of theophylline occurs more rapidly (within 2-4 days).

Our data, although obtained in a small number of patients, support recent studies that demonstrate that theophylline has anti-inflammatory activities [22]. In particular, there is substantial experimental evidence that theophylline inhibits eosinophil recruitment [23] as well as eosinophil derived neurotoxin and ECP secretion [24] and eosinophil chemotaxis [25]. Furthermore theophylline has been shown to induce in vitro apoptosis of eosinophils [26]. Theophylline may have also affected mast cells. It has been shown that theophylline at therapeutic concentrations reduces the amount of antigen-induced mediator release from mast cells [13]. Moreover, in patients with perennial rhinitis, it has been shown that mast cells are an important source of preformed cytokines such as interleukin (IL)-5 [27]. The latter cytokine is a potent growth and differentiation factor, activator, and chemoattractant for eosinophils [28]. It is possible, therefore, that an effect of theophylline on mast cells may explain, at least in part, the decrease in the number of eosinophils and nasal fluid ECP concentration observed with theophylline. These anti-inflammatory effects of theophylline are also supported by a recent study of an asthmatic subject [29]. In this study, theophylline markedly enhanced IL-10 production by peripheral blood mononuclear cells. Recent findings indicate that IL-10 might prevent allergic inflammation induced by T-lymphocyte helper 2 (Th2) by inhibiting the production of cyto- kines involved in the differentiation, activation and recruitment of eosinophils as well as by direct suppressive effects on eosinophils and mast cells [30]. In this context, it has been shown that the production of IL- 5 by activated T-cells is a key event in the induction of eosinophilic inflammation [30], which is an important feature of allergic disease such as allergic rhinitis and bronchial asthma. In humans, IL-10 was found to inhibit IL-5 synthesis by resting CD4+ Tcells and by differentiated Th0 or Th2 clones [31]. Thus, by enhancing IL-10 production [29], theophylline might be useful in controlling Th2 mediated inflammatory processes that are involved in the accumulation of activated eosinophils in target tissues.

Whatever the exact anti-inflammatory effects of theophylline and particularly on eosinophils, it should be noted that in our study at the time of maximal allergen dose, theophylline significantly decreased nasal obstruction. For $200 \mu$ g fluticasone-day-1, LozewICz et al. [32] found an effect on nasal obstruction of the same order of magnitude. Although it is difficult to compare drug effects between various studies with different set-ups and different patients, one might conjecture that the efficacy of oral theophylline is comparable to that of nasal steroids. This effect of theophylline on nasal inflammation and obstruction may be clinically relevant in patients with asthma since several studies have shown the frequent association between both diseases [1]. However, the present study is merely an experimental provocation study with all its limitations. Additional studies are needed to confirm this, and to evaluate further the potential clinical effects of theophylline on the nasal inflammatory processes and symptoms of patients with allergic rhinitis as well as the potential beneficial effect of theophylline on airway hyperresponsiveness frequently observed in patients with allergic rhinitis.

\section{References}

1. Smith JM. Epidemiology and natural history of asthma, allergic rhinitis and atopic dermatitis (eczema). In: Middleton E Jr, Reed CE, Ellis E, Adkinson NF Jr, Yungingh JW, eds. Allergy: Principles and Practice. Vol. 2. St. Louis, C.V. Mosby, 1988; pp. 891-929.

2. Pipkorn U, Karlsson G, Enerback L. The cellular response of the human allergic mucosa to natural allergen exposure. J Allergy Clin Immunol 1988; 82: 1046-1054.

3. Bascom R, Pipkorn U, Lichtenstein LM, Naclerio RM. The influx of inflammatory cells into nasal washings during the late response to antigen challenge: effect of systemic steroid treatment. Am Rev Respir Dis 1988; 138: 406-412.

4. Gleich G, Flavahan N, Fujisawa T, Vanhoutte PM. The eosinophil as a mediator of damage to respiratory epithelium: a model for bronchial hyperreactivity. J Allergy Clin Immunol 1988; 81: 776-781.

5. Shaw RJ, Fitzharris P, Cromwell O, Wardlow AJ, Kay $\mathrm{AB}$. Allergen-induced release of subphidopeptide leukotrienes (SRS-A) and $\mathrm{LTB}_{4}$ in allergic rhinitis. Allergy 1985; 40: 1-6.

6. Weller PF, Lee CW, Foster DW, Corey EJ, Ansten KF, Lewis RA. Generation and metabolism of 5-lipoxygenase pathway leukotrienes by human eosinophils: predominant production of leukotriene C4. Proc Natl Acad Sci USA 1983; 80: 7626-7630. 
7. Barnes PJ, Pauwels RA. Theophylline in the management of asthma: time for reappraisal? Eur Respir J 1994; 7 : 579-591.

8. Sullivan P, Bekir S, Jaffar Z, Page C, Jeffery P, Costello J. Anti-asthmatic effects of low-dose oral theophylline in atopic asthma. Lancet 1994; 343: 1006-1008.

9. Kidney J, Dominguez M, Taylor PM, Rose M, Chung KF, Barnes P. Immunomodulation by theophylline in asthma. Demonstration by withdrawal of therapy. Am J Respir Crit Care Med 1995; 151: 1907-1914.

10. Finnerty JP, Djukanovic R, Madden J, Holgate ST. Effects of theophylline on inflammatory cells and cytokines in asthmatic subjects: a placebo controlled parallel group study. Eur Respir J 1996; 9: 1672-1677.

11. Venge P, Dahl R, Karlström R, Pedersen B, Peterson CGB. Eosinophil and neutrophil activity in asthma in a one-year double-blind trial with theophylline and two doses of budesonide. J Allergy Clin Immunol 1992; 89: 190.

12. Rabe KF, Magnussen H, Dent G. Theophylline and selective PDE inhibitors as bronchodilators and smooth muscle relaxants. Eur Respir J 1995; 8: 637-642.

13. Naclerio RM, Bartenfelder D, Proud D. Theophylline reduces histamine release during pollen-induced rhinitis. J Allergy Clin Immunol 1986; 78: 874-876.

14. Aubier M, Levy J, Clerici C, Neukirch F, Cabrieres F, Herman D. Protective effect of theophylline on bronchial hyperresponsiveness in patients with allergic rhinitis. Am Rev Respir Dis 1991; 143: 346-350.

15. Bisgaard H, Gronborg H, Mygind N, Dahl R, Lindquist $\mathrm{N}$, Venge P. Allergen-induced increase of eosinophil cationic protein in nasal lavage fluid: effect of the glucocorticoid budesonide. J Allergy Clin Immunol 1990; 85: 891-895.

16. Taylor G, Macneil AR, Freed DL. Assessing degree of nasal patency by measuring peak expiratory flow rate through the nose. J Allergy Clin Immunol 1973; 52: 193198.

17. Dehoux MS, Boutten A, Ostinelli J, et al. Compartmentalized cytokine production within the human lung in unilateral pneumonia. Am J Respir Crit Care Med 1994; 150: 710-716.

18. Aubier M, Levy J, Clerici C, Neukirch F, Herman D. Different effects of nasal and bronchial glucocorticosteroid administration on bronchial hyperresponsiveness in patients with allergic rhinitis. Am Rev Respir Dis 1992; 146: 122-126.

19. Pipkorn U, Proud D, Lichtenstein LM, et al. Effect of short-term systemic glucocorticoid treatment on human nasal mediator release after antigen challenge. J Clin Invest 1987; 80: 957-961.

20. Dutoit JL, Salmone CM, Woolcock AJ. Inhaled corticosteroids reduce the severity of bronchial hyperresponsiveness in asthma but oral theophylline doses not. Am Rev Respir Dis 1987; 138: 1174-1178.

21. Pastorello EA, Riario-Sforza GG, Incorvaia C, Segala M, Fumagalli M, Gandini R. Comparison of rhinomanometry, symptoms score, and inflammatory cell counts in assessing the nasal late-phase reaction to allergen challenge. J Allergy Clin Immunol 1994; 93: 85-92.

22. Aubier M, Barnes PJ. Theophylline and phosphodiesterase inhibitors. Eur Respir J 1995; 8: 347-348.

23. Gozzard N, Hend CM, Blake SM, et al. Effects of theophylline and solipram an antigen-induced airway responses in nesnatally rabbits. Br J Pharmacol 1996; 117: 1405-1412.

24. Hatzelmann A, Tenor H, Schudt C. Differential effects of non-selective and selective phosphodiesterase inhibitors on human eosinophil functions. Br J Pharmacol 1995; 114: 821-831.

25. Schudt C, Tenor H, Hatzelmann A. PDE isoenzymes as targets for antiasthmatic drugs. Eur Respir J 1995; 8: $1179-1183$.

26. Ohta K, Sawamoto S, Nakajima M, Nagai A, Tanaka Y, Hirai K. Theophylline induces apoptosis in eosinophils surviving with interleukin-5 in vitro. J Allergy Clin Immunol 1994; 93: 200-206.

27. Bradding P, Feather IH, Wilson S, et al. Immunolocalization of cytokines in the nasal mucosa of normal and perennial rhinitic subjects. Journal of Immunology 1993; 151: 3853-3865.

28. Lopez AF, Sanderson CJ, Gamble JR, Campbell HR, Young IG, Vadas MA. Recombinant human interleukin 5 is a selective activator of human eosinophil function. $J$ Exp Med 1988; 167: 219-225.

29. Mascali JJ, Cuietusa P, Negri J, Borish L. Anti-inflammatory effects of theophylline: modulation of cytokine production. Ann Allergy Asthma Immunol 1996; 77: 34-38.

30. Pretolani M, Goldman M. IL-10: a potential therapy for allergic inflammation? Immunology Today 1997; 18: 277-280.

31. Marshall JS, Leal-Berumen I, Nielsen L, Glibetic M, Jordana M. Interleukin IL-10 inhibits long-term IL-6 production but not preformed mediator release from rat peritoneal mast cells. J Clin Invest 1996; 97: 1122-1128.

32. Lozewicz S, Wang J, Duddle J, et al. Topical glucocorticoids inhibit activation by allergen in the upper respiratory tract. J Allergy Clin Immunol 1992; 89: 951-957. 